\title{
A systemic and cognitive view on collaborative knowledge building with wikis
}

\author{
Ulrike Cress • Joachim Kimmerle
}

Received: 22 February 2007 / Accepted: 26 November 2007 /

Published online: 10 January 2008

(C) International Society of the Learning Sciences, Inc.; Springer Science + Business Media, LLC 2008

\begin{abstract}
Wikis provide new opportunities for learning and for collaborative knowledge building as well as for understanding these processes. This article presents a theoretical framework for describing how learning and collaborative knowledge building take place. In order to understand these processes, three aspects need to be considered: the social processes facilitated by a wiki, the cognitive processes of the users, and how both processes influence each other mutually. For this purpose, the model presented in this article borrows from the systemic approach of Luhmann as well as from Piaget's theory of equilibration and combines these approaches. The model analyzes processes which take place in the social system of a wiki as well as in the cognitive systems of the users. The model also describes learning activities as processes of externalization and internalization. Individual learning happens through internal processes of assimilation and accommodation, whereas changes in a wiki are due to activities of external assimilation and accommodation which in turn lead to collaborative knowledge building. This article provides empirical examples for these equilibration activities by analyzing Wikipedia articles. Equilibration activities are described as being caused by subjectively perceived incongruities between an individuals' knowledge and the information provided by a wiki. Incongruities of medium level cause cognitive conflicts which in turn activate the described processes of equilibration and facilitate individual learning and collaborative knowledge building.
\end{abstract}

Keywords Collaboration $\cdot$ Computer support $\cdot$ Knowledge building $\cdot$ Equilibration $\cdot$ Wiki

\footnotetext{
U. Cress $(\square)$

Knowledge Media Research Center, Konrad-Adenauer-Str. 40, 72072 Tuebingen, Germany e-mail: u.cress@iwm-kmrc.de

J. Kimmerle

Department of Applied Cognitive Psychology and Media Psychology, University of Tuebingen, Konrad-Adenauer-Str. 40, 72072 Tuebingen, Germany

e-mail: j.kimmerle@iwm-kmrc.de
} 


\section{Introduction}

Recently, a variety of new tools and technologies fostering computer-supported collaborative learning (CSCL) and computer-supported cooperative working (CSCW) appeared and established themselves on the Internet (Beldarrain 2006; Bryant 2006). This development is frequently referred to as Web 2.0 (Bridsall 2007; Murugesan 2007). On the one hand, the term Web 2.0 describes a set of new interactive technologies and services on the internet (Richardson 2006). On the other hand, it refers to a modified utilization of information (Tredinnick 2006). What is of particular importance in the Web 2.0 context for CSCL researchers is the integration of so-called social software (Kesim and Agaoglu 2007; Kolbitsch and Maurer 2006). Social software refers to systems which facilitate human communication, interaction, and collaboration in large communities (Wagner and Bolloju 2005; Ward 2006). These systems support the constitution and maintenance of self-organizing social networks and communities (Köhler and Fuchs-Kittowski 2005; Lin et al. 2006; Moore and Serva 2007; Wasko and Faraj 2005). Weblogs (blogs), file-sharing communities, and especially wikis loom large in this social-software context (Wagner and Bolloju 2005). Blogs are websites which are used as online diaries (Chau and Xu 2007). They periodically contain new entries. Usually, blogs are produced by a single author or by a small group of users (Moore and Serva 2007; Sweetser and Metzgar 2007), but they are open to the public for reading (Blood 2002; Maurer and Tochtermann 2002). Blogs can be used for purposes of learning and knowledge sharing (Ras et al. 2005). However, contrary to wikis, entries in blogs cannot be changed anymore by other users. File-sharing web pages provide private spaces where users can store their documents, and a public space where files can be shared with other users (Ceballos and Gorricho 2006). Popular examples of file-sharing communities are services such as photo-sharing or video-sharing websites (Rodriguez et al. 2005).

Whereas blogs and file-sharing systems mainly serve for pooling information, wikis have special potential for computer-supported collaborative knowledge building and learning (Bruns and Humphreys 2005; Chong and Yamamoto 2006; Kim et al. 2006; Reinhold 2006; Wang and Turner 2005; Yukawa 2006).

Wikis' potential for collaborative knowledge building

As we agree with Scardamalia and Bereiter (2003) who emphasize the importance of knowledge-creating competencies "in a knowledge society" (Scardamalia 2002, p. 67), we wish to point out the necessity of systematically analyzing the potential of wikis as tools for knowledge building. Wikis are web sites which allow users not only to have access to its content but also to change the content online (Leuf and Cunningham 2001; Raitman et al. 2005). Wikis are not only available in the WWW but can also be implemented in intranets or on local computers. Wikis do not require software, are easily accessible, and are simple to use for everybody (Désilets et al. 2005). These qualities make wikis valuable tools for a multitude of purposes (Joyce 2005). Wikis are used for knowledge-management (FuchsKittowski and Köhler 2005; Wagner 2006; Wagner and Bolloju 2005) as well as for educational purposes (Bruns and Humphreys 2005; Chong and Yamamoto 2006; Notari 2006; Wang and Turner 2005); in economical (Wagner and Majchrzak 2007) or in political contexts (Makice 2006). Wikis are mostly used to develop written text. Their special feature is that people can do all kinds of revision of the text: they can create hyperlinks and fill them with content, they can revise a text by adding, deleting, or changing any parts they want to (Raitman et al. 2005). In this way, large groups of like-minded people are able to work collaboratively on one and the same text about a certain topic. In wikis, all users 
jointly create one hypertext, an activity which allows the collaborative generation of knowledge (Fuchs-Kittowski and Köhler 2005; Köhler and Fuchs-Kittowski 2005). Wikis' potential for collaborative learning lies in their ability to allow for debate-based learning experiences (Chong and Yamamoto 2006) or to facilitate shaping of knowledge (Reinhold 2006). Wikis can be regarded as media which support learning due to their ability to facilitate collaboration (Kim et al. 2006; Notari 2006), to allow for design-based learning (Rick and Guzdial 2006), to enhance inventiveness (Guzdial et al. 2001), and to support inquiry learning and the co-construction of knowledge (Yukawa 2006). Overall, wikis can be considered to support social constructivist learning in general (Bruns and Humphreys 2005).

Collaborative activities in wikis give rise to, for example, the production of encyclopedias or dictionaries (Joyce 2005). An example which illustrates the potential of wikis is the online encyclopedia Wikipedia (Korfiatis et al. 2006; Lih 2004; Pentzold and Seidenglanz 2006; Wagner 2006). Here, users collaboratively develop the world's largest encyclopedia. Every internet user is allowed to participate in this undertaking. The Wikipedia example will be applied in this article in order to make our theoretical analysis more concrete. In a wiki people work jointly on one common artifact (cf. Stahl 2002 for the relevance of artifacts in CSCL). And a multitude of people around the world are able to participate in this process anywhere and at anytime. In this article we will ask what makes wikis supportive of learning and knowledge building ${ }^{1}$ (for the particular importance of knowledge building for CSCL cf. Hewitt and Scardamalia 1998; or Scardamalia and Bereiter 1996). To examine this question, our considerations will be based on fundamental perspectives on learning and knowledge building (for diverse implementations of knowledge-building principles in CSCL cf. Kali 2006; Lee et al. 2006; Oshima et al. 2006). We presuppose that a person's individual knowledge can serve as a resource for other peoples' learning (Kafai 2006; Scardamalia and Bereiter 1994). We base our arguments on findings as to how people make use of each others' knowledge through collaborative knowledge building with artifacts (Bruckman 2006; Norman 1991). In this regard we refer to Papert's approach of constructionism (e.g. Papert 1980, 1987, 1993, 1997; cf. also Kafai 2006) pointing out that our perspective is grounded in a tradition that emphasizes the learner's active participation in the learning process (cf. Greeno 2006; for a contribution considering this activity approach in wiki research cf. Notari 2006; for an approach analyzing constructivist learning on the WWW cf. Wilson and Lowry 2001).

In the remainder of this article we will present a theoretical model of collaborative knowledge building with wikis by assuming a systemic perspective. In this context we will discuss the differential modes of operation in social and cognitive systems. Psychological research has described the cognitive processes responsible for individual learning as assimilation and accommodation. The question arises if there are equivalent processes in social systems such as wikis. Since we are convinced there are equivalent processes, we present this article to lead to a better understanding of the processes of collaborative knowledge building. In the following presentation, we will distinguish between the processes of externalization and internalization. We will clarify these processes by applying Wikipedia examples to our model in order to illustrate our notions and to provide an empirical basis. We will then describe the four processes of learning and knowledge building that result from the distinction between external and internal processes on the one hand, and between assimilation and accommodation on the other hand. Finally, we will describe the motivational aspects of collaborative knowledge building with wikis. We attribute people's motivation to participate in collaborative knowledge building to their

\footnotetext{
${ }^{1}$ Of course, wikis do not only have advantages. However, as this is an article about the potential of wikis for collaborative knowledge building, possible shortcomings will not take center stage in this analysis.
} 
perception of incongruities and to the perceived valence of the topic. We are aware that, in the strict sense, the motivational aspects are intrinsically tied to the processes of knowledge building, and that the cognitive and socio-cognitive processes cannot be separated from the motivational ones. However, we decided to present our model in an order which makes clear that the cognitive and the socio-cognitive processes can help to explain the motivational processes. Therefore, for the purpose of clarity and examination, we are obliged to isolate our presentation of the motivational aspects.

\section{A Model of collaborative knowledge building with wikis}

In the model presented here we consider from a systemic point of view the processes necessary for the exchange of knowledge and for collaborative knowledge building with wikis. For this purpose we borrow perspectives from systems theoretical approaches (cf. Luhmann 1984, 1995, 1997; von Bertalanffy 1950, 1968). According to Luhmann's sociological systems theory social systems can be distinguished from cognitive systems. In this section we will first of all outline the functionality of a social system, and then we will address the functionality of cognitive systems. After that, we will describe the processes responsible for transitions between the social system and people's cognitive systems. In this context, we distinguish the process of externalization from the process of internalization, and we describe both processes in detail. In order to present our ideas as comprehensibly as possible, we will first introduce the major concepts on a general level, and then we will explain them in more detail, applying real-life examples from Wikipedia.

\section{Social and cognitive systems}

Luhmann describes systems as dynamic, that is, they develop over time and consist of operations. A system ceases where its mode of operation ceases. Such operations are defined as the production of elements with the help of the elements of the same system. This definition implies that systems are autopoietic and self-referential. They produce their own elements (for a detailed elaboration on the phenomenon of autopoiesis cf. Maturana and Varela 1980; Varela et al. 1974; or Luhmann 1986, 1990). Luhmann presumes that systems continuously develop and recreate themselves. This way, autopoiesis guarantees the system's permanent continuance. In other words, systems exist due to operations which are followed by further operations of the same kind and so on. That means subsequent operations always build on the results of preceding operations.

Luhmann distinguishes three different kinds of systems: Biological systems operate by means of biological processes. They are autopoietic in the sense that cells create other cells. Psychological or cognitive systems operate via processes of consciousness and cognitive processes, such as retrieval of knowledge from long-term memory (Baddeley 1986, 1992), elaboration of knowledge (Craik and Lockhart 1972), or processes of externalization and internalization of knowledge. They are also autopoietic as cognitions develop further cognitions. Finally, social systems operate by means of communication. In this context, communication is not intended to be a result of people's activities but a product of social systems.

Each system selects its own elements by establishing a criterion for difference. For this purpose the system applies a specific "binary code": the social system "arts", for example, applies a binary code which decides if something is aesthetic or not, the system "science" applies a binary code which decides if something is valid or not, or the systems "politics" applies a code which decides if something has to do with power or not. Applying such a binary code is the way systems operate and develop. 
From a system's perspective the environment is contingent. This means the system cannot anticipate what will happen in the environment, and thus, the environment can irritate the system. So, for each system its environment is more complex than the system itself. But after being irritated, a system may be able to select a limited amount of information available outside its borders. By operating on this information it reduces external complexity, establishes new elements and relations, and thus increases its internal complexity.

Social systems depend on cognitive systems, because there would be no communication without cognitions. Luhmann points out that systems are operationally closed, i.e. every system has an idiosyncratic mode of operation, social and cognitive systems cannot directly correspond with each other. Nevertheless, systems can influence each other, e.g., the social system wiki responds to stimuli from cognitive systems. In order to solve the problem of systems that are open and closed at the same time, Luhmann applies the concept of structural coupling. Social systems are structurally coupled with cognitive systems via language. Since systems are sensitive to irritations from their environment, and since irritations can be incorporated into system-immanent operations, different systems can make use of other systems' complexity. So a cognitive system, for example, can take on the social system's elements and the social system can take on the cognitive system's elements if they irritate each other. So structural coupling allows for a co-evolution of both systems. Both systems, the cognitive and the social system, can become more and more complex over time.

Since social and cognitive processes have to be considered separately in the first instance, it is all the more interesting to examine what results from their interplay. Consequently, clearly delineating the "border" between the social system (here: the wiki) and the cognitive systems (of the users) is crucial for understanding how collaborative knowledge building works. What processes are going on when people share their knowledge by creating wikis? What is happening when people work mutually on one common artifact, thereby introducing their knowledge to the community and building new knowledge collaboratively?

In the approach presented here, we propose two processes as the basis for the "crossing of the border" between the social and the cognitive system: we refer to these processes as "externalization" and "internalization" respectively.

\section{Externalization $^{2}$}

For contributing to the development of a wiki, people first have to externalize their knowledge (Klein 1999). They do this by introducing information which reflects their own knowledge. For that purpose, a person's own knowledge has to be conveyed into a wiki article in a form that maps the person's knowledge.

The wiki article, then, exists independently from the people who created it, and it develops in a way that is determined by people's knowledge. The information in the wiki relates to the contributor's individual knowledge: therefore, the person's cognitive processes are represented by and reflected in the wiki. A user is only able to contribute something to a wiki if she or he has corresponding knowledge about that topic. Of course, the information in the wiki and the knowledge in a person's mind are not identical, but they

\footnotetext{
${ }^{2}$ At this point it has to be emphasized that "externalization" and "internalization" are meant from the cognitive system's point of view. What externalization is from the cognitive system's perspective can be considered internalization from the social system's perspective and vice versa.
} 
are equivalent to a certain degree. After the process of externalization, the wiki exists independently from the person's knowledge.

Contributing to an article does not only allow the creation of an artifact, it can also lead to individual learning processes in the contributors. The mental effort necessary for the externalization of knowledge can extend people's individual knowledge, because externalization requires deeper processing and clarification. This aspect is addressed by the work of Flower and Hayes (1980) as well as Webb (1982). So normally, people who contribute to a wiki article cannot externalize their own knowledge without some changes in their individual knowledge. Through the externalization process people often deepen their knowledge and clarify their understanding. So externalization can lead to individual learning processes, and people who contribute to a wiki article can expand their own individual knowledge.

These processes are tentatively presented in Fig. 1. This illustration is unavoidably a makeshift one, since the matter's procedural character cannot be expressed adequately in a static figure. In Fig. 1 this learning process is displayed by the grey symbols which expand the cognitive systems CS to CS'. In this figure each symbol represents another aspect of knowledge. Each of the three people externalizes knowledge by contributing to the wiki, and person 1 and 3 develop new knowledge through this activity.

Once a person has contributed to a wiki, then each individual group member can have access to the wiki's information. This is indicated by the symbols within the wiki in Fig. 1.

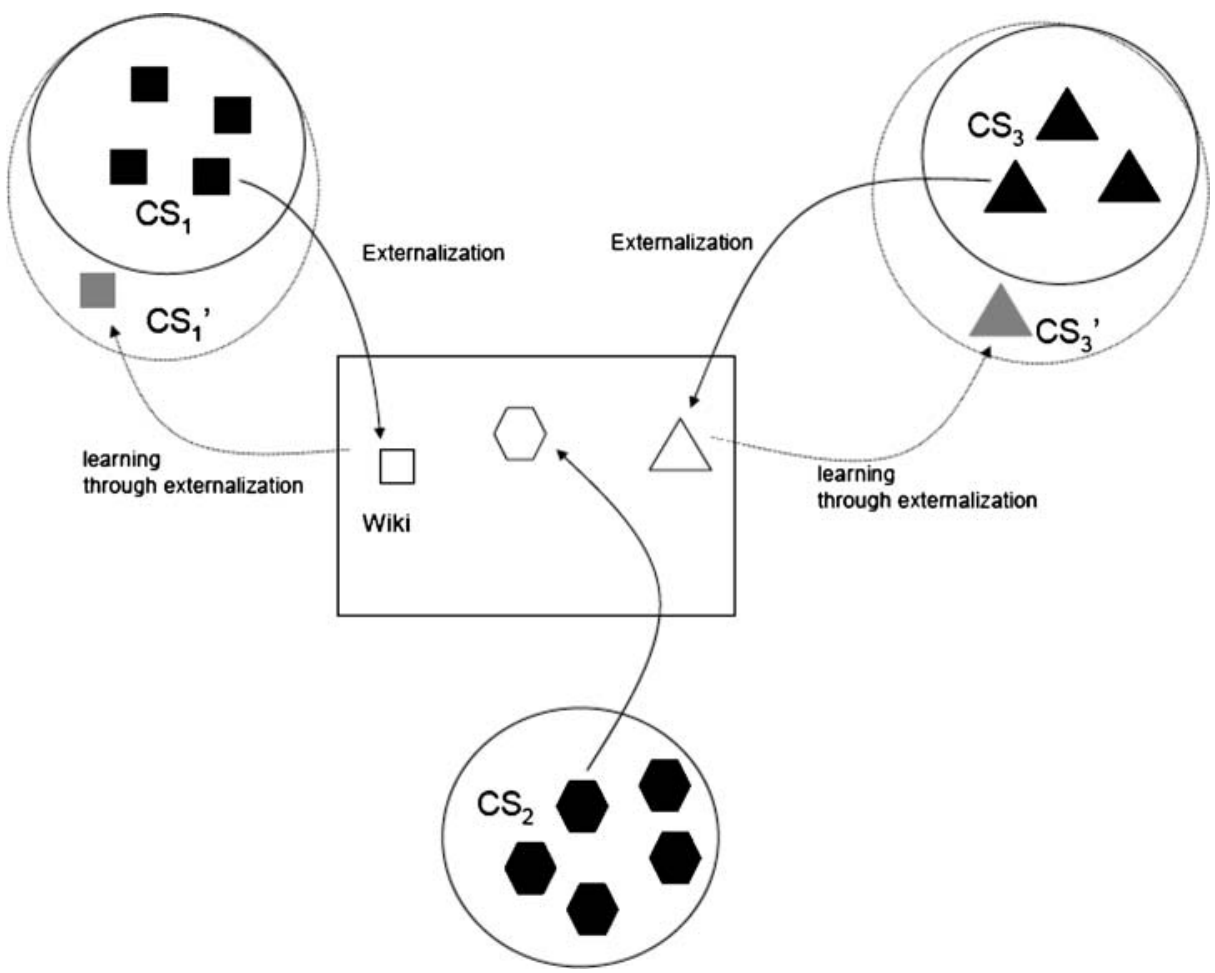

Fig. 1 Three cognitive systems $\left(\mathrm{CS}_{1}\right.$ to $\left.\mathrm{CS}_{3}\right)$ and the social system wiki. The grey symbols represent novel aspects of knowledge as a result of learning through externalization. $\mathrm{CS}_{1}{ }^{\prime}$ and $\mathrm{CS}_{3}{ }^{\prime}$ represent extended cognitive systems correspondingly 
For the time being, this process of externalization does not require the interaction with other people in a narrow sense. People can externalize their knowledge (and thereby extend their own knowledge) without necessarily addressing other people in the first place. However, with respect to the process of internalization, which will be described in the next section, participation of other people is indispensable.

\section{Internalization}

Inter-individual knowledge transfer and collaborative knowledge building take place when people have the opportunity to work with a wiki and to internalize the information available in the wiki. So people have to process the information and integrate it into their individual knowledge. Through this internalization people develop new knowledge, i.e. people use the wiki's information to expand their own knowledge. In Fig. 2 the results of such an internalization process is indicated by the striped symbols. Through internalization a cognitive system is expanded to CS".

Besides this individual creation of knowledge resulting from the internalization of information in a wiki, an additional kind of knowledge-creating process can occur: If people internalize information from the wiki, knowledge can develop which was formerly neither part of their personal knowledge nor part of the wiki. Such additional knowledge development can happen if new knowledge that people have internalized from a wiki interacts with their prior individual knowledge in a way that enables people to create new

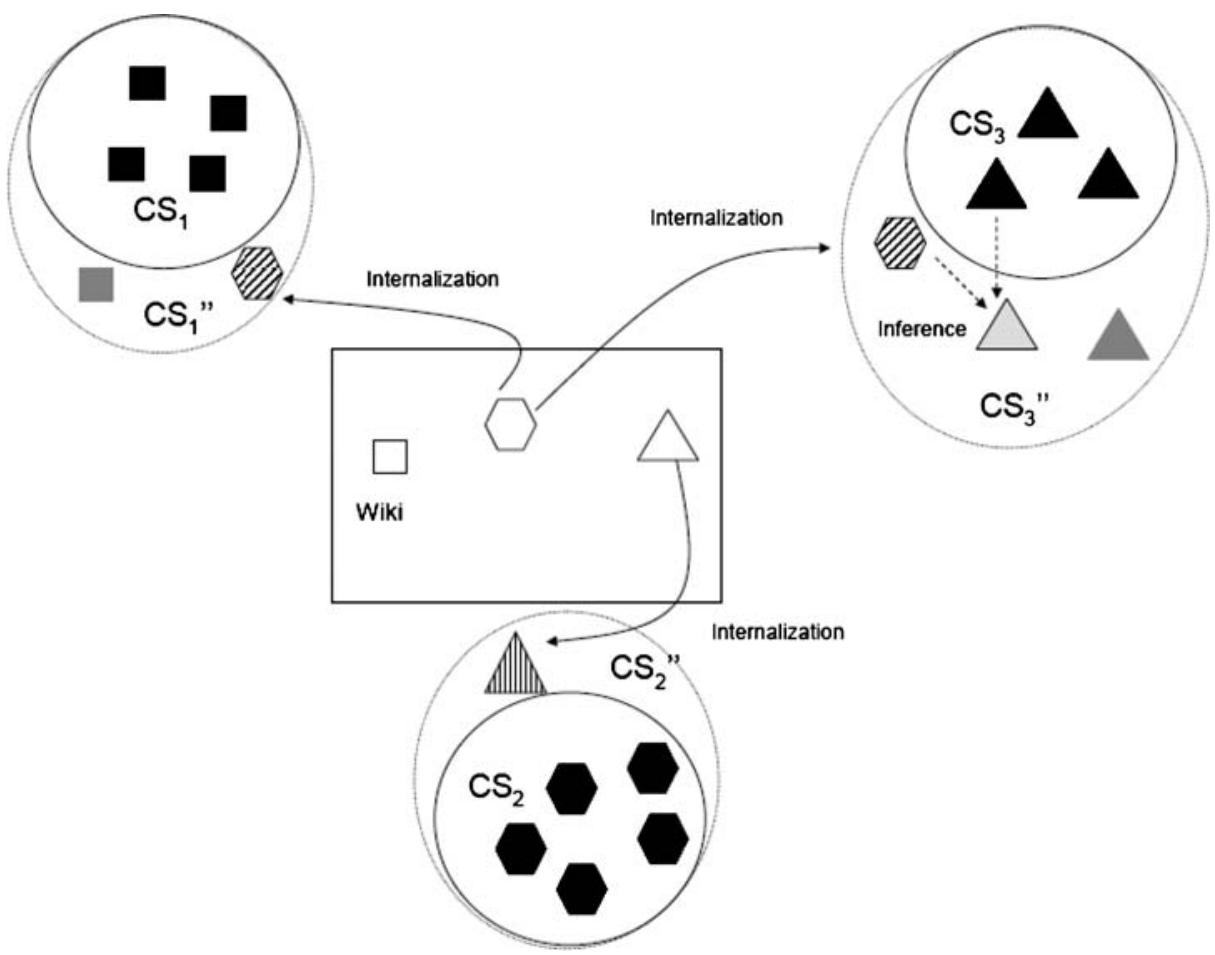

Fig. 2 Process of internalization: Each of the three cognitive systems internalizes information (striped symbols). $\mathrm{CS}_{3}$ additionally develops new knowledge (light-grey) through a process of inference from internalized knowledge and prior knowledge. The occurrence of such knowledge shows an emergent process 
knowledge, i.e. if people are able to infer new knowledge out of the knowledge they internalized through the work with the wiki and the knowledge they had before. This knowledge can be described as emergent knowledge. A person would not have been able to create this knowledge if she or he had not been internalizing information from work with the wiki. This emergent knowledge is a result of the collaboration and as such represents collaborative knowledge building which is more than mere knowledge sharing. In collaborative knowledge building something qualitatively new has developed. Emergent knowledge has not been part of the individual's knowledge before (for more elaborate detail on the phenomenon of emergence cf. Holland 1998 or Johnson 2001). In Fig. 2 the cognitive system 3 has developed such emergent knowledge.

\section{Four processes of learning and knowledge building}

The model so far has described different kinds of individual learning. Individual learning occurs as a result of externalization (due to processes of deeper elaboration which are activated by the externalization process). And individual learning occurs as a result of internalization (due to the simple adding of new knowledge or due to the expansion of a person's individual knowledge through internalization and, arising from that, an opportunity to interconnect old and new knowledge). All forms of learning take place when people interact with the wiki in a way that knowledge and information are interchanged between the individual's cognitive system and the wiki. So, to refer back to Luhmann's perspective, learning occurs by the crossing of the border between the individual's cognitive system and the wiki. The processes of internalization and externalization cause these individual learning processes. And processes of structural coupling and mutual irritation may enable the coevolution of the users' knowledge and the wiki's content.

To facilitate being able to describe the complex processes of this co-evolution it is reasonable to make use of theories which describe cognitive processes of individual learning. A prominent approach that describes how people deal with new information is Piaget's model of equilibration (Piaget 1970, 1977a and b). This model explains how people take in new information from their environment, then how they perceive and encode this information from outside and integrate it into their own knowledge. The equilibrium theory describes the way people try to maintain a balance between the environmental information on the one hand and their prior knowledge on the other hand. If information is new and not in line with existing knowledge this incongruity causes a cognitive conflict. When information cannot be promptly decoded and integrated into existing knowledge, people have to adapt to this new environment (cf. also the taxonomy of responses in anomalous data provided by Chinn and Brewer 1993, 1998). Piaget points out that such cognitive conflicts can lead to new knowledge. There are two possibilities to solve a cognitive conflict, i.e. two ways of adaptation: people can assimilate the new information or they can accommodate their knowledge (in order to make it compatible with the information). Assimilation describes a process where an individual understands new information on the basis of existing knowledge and then integrates the information into prior knowledge. This means that information coming from the environment is perceived and modified in a way that makes it fit into the individual's knowledge. Assimilation describes predominantly a quantitative aspect of individual learning. An individual's knowledge remains pretty much the same and only additional pieces of information which fit into this knowledge are added.

The other process of adaptation which Piaget describes is the process of accommodation. Here, people interact with new information in a way that changes their knowledge. In this 
case, people do not simply assimilate new information into existing knowledge, but actually change knowledge in order to better understand the environment and its information. In contrast to the quantitative process of assimilation, we consider the creation of new knowledge, in the process of accommodation, as an indicator of learning in a qualitative manner.

We apply this distinction between assimilation and accommodation to our model of people's interaction with wikis. When interacting with the wiki, people can learn as a result of externalization, or as a result of internalization (with or without inferences). This learning can take place by assimilation or by accommodation respectively: people can extend their knowledge by simply adding new information, or they can modify their prior knowledge and create new knowledge.

For collaborative knowledge building with wikis, we state that accommodation and assimilation do not only take place internally (in people's cognitive systems) but also externally (in the social system wiki). It is proposed that a wiki can be made to accommodate or assimilate as well (Majchrzak et al. 2006) draw a similar distinction by categorizing contributors to a wiki as "adders" and "synthesizers"). If information is contributed to the wiki without being linked to previously existing information, the wiki is only extended by the addition of some information. If information is contributed this way, the wiki assimilates the new information, which means that the organization of the wiki remains the same, only some information is added. Majchrzak et al. (2006), examining users of a corporate wiki, found as well that the mere adding of information can be observed very often. The authors report that this activity comprises either simply adding content to existing pages or adding new pages.

Besides assimilating information the wiki can also accommodate. This happens when new information is not only attached to the existing information, but the information in the wiki is organized in a new way. Majchrzak et al. (2006) also report activities that correspond to accommodation processes. With respect to the corporate wiki examined by the authors these processes play an important role. Accommodation processes incorporate the integration of ideas which have already been contributed, the reorganization of pages, or the rewriting of complete paragraphs.

In sum, in collaborative knowledge building with wikis four different forms of learning and knowledge building can be distinguished: Internal assimilation (quantitative individual learning), internal accommodation (qualitative individual learning), external assimilation (quantitative knowledge building), and external accommodation (qualitative knowledge building). The first two are processes of individual learning; the latter two are processes of a collaborative knowledge building with respect to the wiki. What is essential with respect to these considerations is that this is a sample situation which helps us understand how cognitive and social systems develop mutually. Luhmann labels this mutual development "co-evolution". This co-evolution of systems constitutes the foundation of collaborative knowledge building.

In order to illustrate the external and internal processes of assimilation and accommodation that are presented in the theoretical model, two articles from the English language version of Wikipedia are applied as examples in the following section (the reader can trace all the descriptions by visiting the articles' history pages in Wikipedia ${ }^{3}$.

\footnotetext{
${ }^{3}$ The current versions of the articles can be found on: http://en.wikipedia.org/wiki/Computer-supported collaborative_learning and on http://en.wikipedia.org/wiki/AIDS_origin respectively.
} 


\section{Empirical evidence}

The first example which is intended to illustrate the model is the article on "Computersupported collaborative learning". The Wikipedia article on "AIDS origin" serves as another example. The CSCL article is an article that with only a few contributions develops rather slowly, while the article on AIDS origin is processed extensively. We have chosen these different articles deliberately in order to show that the processes which we describe do not depend on the speed of development.

According to Luhmann (1995) a social system operates via communication. In the case of wikis this is text-based communication. With respect to Wikipedia the wiki community establishes itself through interaction and collaboration which results in written encyclopedia articles. The wiki articles comprise the information people share.

\section{Example 1: "Computer-supported collaborative learning"}

In the following text we provide concrete examples for the processes of assimilation and accommodation in the wiki.

The Wikipedia article on CSCL was established by one user who knew that there is a field called CSCL and decided to write an article on this topic. On the 28th of March 2006 this user created an article and contributed some information on the general goals and purposes of CSCL. On the 29th of August 2006 another user read the provided information, decided to act in response to this information, and contributed some external links she or he considered useful in the context of CSCL and so on. This way, communicative processes take place, and the CSCL article continues to develop out of provided information and becomes more and more complete. The wiki develops autopoietically by operations building on preceding operations.

The articles are traceable on the internet where they are accessible for all members of the community. Each member can contribute to an article. On the one hand, she or he can extend or diminish an article by adding or deleting information. On the other hand, a participant can change the artifact's structure by revising an article. In this sample article both processes of assimilation as well as processes of accommodation can be found.

If we compare, for example, the first version on the 20th of February 2007 with the preceding version we find that there was only an external link (the CSILE/Knowledge Forum link) added. With regard to our presented model we describe this process as an external assimilation. A user simply added a link without any further changes of the previous text. It could be that the user knows more about CSILE and would be able to describe in deeper detail how CSILE fits to CSCL and what significance CSILE has for the development of CSCL, but she or he did not describe this explicitly. In the article's history we only see that this person first simply added the link and named it "CSILE (Computersupported intentional learning environment)/ Knowledge Forum", then - a few minutes later - she or he made a small extension and added "CSILE, the first CSCL environment, and its second generation: Knowledge Forum". Another reader of the article can interpret this link on the basis of the existing article about CSCL. She or he learns that CSILE was the first environment for CSCL. But this information does not change the information of the article in a deeper way, it is only an amendment. So this represents an example for an external assimilation.

However, information was not only simply attached to the existing information in the CSCL article, but there is also evidence that information in the wiki was also organized in a new way and major concepts were changed in their meaning. For example, this happened in 
the first version on the 8th of June 2007. On the left hand side of the following schema the previous version can be seen, the right hand side presents the later version ${ }^{4}$. The sentences have been numbered for reference purposes.

A1 "CSCL supports and facilitates group processes and group dynamics in ways that are not achievable by face-to-face, but they are not designed to replace face-to-face communication"

A2 "This type of learning is typically tailored for use by multiple learners working at the same workstation or across networked machines, working synchronously or asynchronously"

A3 "The purpose of CSCL is to scaffold or support students in learning together effectively"

A4 "This system can support communicating ideas and information, accessing information and documents, and providing feedback on problem-solving activities"

\section{“..."}

B2 "CSCL is a major method for bringing the benefits of collaboration and cooperative learning to users of distance learning via networked computers, such as the courses offered via the Internet"

B3 "The purpose of CSCL is to scaffold or support students in learning together effectively"

B4 "CSCL supports the communication of ideas and information among learners, collaborative accessing of information and documents, and instructor and peer feedback on learning activities"

B5 "CSCL also supports and facilitates group processes and group dynamics in ways that are not achievable by face-to-face communication (such as having learners label aspects of their communication)"

"..."

B6 "Due to the surge of distance learning via the Internet, including courses that employ CSCL, it is important that educators and instructional designers better understand the benefits and limitations of CSCL"

A7 "CSCL is much more ambitious than previous approaches of ICT-support in education"

A8 "It is therefore more difficult to evaluate the effectiveness and efficiency of CSCL activities"

A9 "Nonetheless, all actors involved in 'elearning', and more specifically in CSCL processes,- - from policy makers to everyday practitioners - need to have evidence of whether, how and when expected improvements in learning take place"

A10 "Significant effort is required to provide systematic evaluation of innovative projects, the specific experiences within an action/ research framework, the new CSCL systems developed, and so on"

\footnotetext{
${ }^{4}$ Typing errors in the original text were not corrected.
}

B8 “... it is difficult to evaluate the effectiveness and efficiency of CSCL activities"

B9 "Early efforts focused on suspected detrimental effects of communication filtering of computer mediated communication (CMC) and ignored the potential benefits of CMC. Historically, the lack of evidence that technological innovations have improved learning in formal education highlights the need for evidence of whether, how and when expected improvements in learning take place" 
The article was revised, the information was rearranged and reconfigured. A1 was moved back to B5, B6 was inserted, and A10 was not accepted. The user emphasized novel aspects, and novel relations became clear. For example A2 was changed in a way that in B2 CSCL is described as aiming to support learners for distance learning and courses offered via internet. In A2 this was much broader and CSCL was referred to "learners working at the same workstation or across networked machines, working synchronously or asynchronously". The author revising the article introduced the aspect of distance learning also in B6. Whereas in A7 it was said that "CSCL is much more ambitious than previous approaches of ICT-support in education", in B7 this is revised into "Like many educational activities...". So in the revised text CSCL is linked very explicitly to distance education, and brings the text to another focus compared to the old text. So we can interpret this revision as an external accommodation, where the orientation of the whole text has changed.

\section{Example 2: "AIDS origin"}

In the following text we provide further examples for the processes of equilibration in Wikipedia. The Wikipedia article about AIDS origin deals with a very controversial topic which led to many revisions, both in terms of assimilation as well as accommodation.

An example for assimilation is the addition of the Russian abbreviation on the 10th of February 2007 (09:27; see footnote 4): "In Russian it got the name SPID (Sindrom Priobretyonnoy Immunitetnoy Defitsitnosti)." On the 6th of May 2007 the Irish abbreviation is added: “... and in Irish SEIF (Siondróm Easpa Imdhíonachta Faighte)”.

As an example for accommodation processes we describe how a contentious theory is integrated into the article. It concerns the theory that blames the research into a polio vaccine for the transition of the AIDS virus to human beings. First of all, the sentence that describes this transition ("[The viruses] most likely got into humans via the hunting and eating of the original primate species. A bite would be another possible route") is changed on the 3rd of March 2006: "Possible ways for this virus to have originally infected humans include the hunting and eating of the original primate species; a bite would be another possible route". This relativized the possible explanation. Later an additional sentence is amended ("From this point, the virus ultimately spread to the rest of the world") which is replaced on the 28th of November 2006 (16:07) by referring to the contentious polio vaccine theory:

"A more controversial theory known as the OPV AIDS hypothesis suggests that the AIDS epidemic was inadvertently started in the late 1950s in the Belgian Congo by Hilary Koprowski's research into a polio vaccine... After the initial transfer of AIDS from primate to human, the virus ultimately spread to the rest of the world."

What we can observe here is the reconsideration of this theory which had been introduced before in the version from the 20th of February 2006:

"One currently controversial possibility for the origin of HIV/AIDS was discussed in a 1992 Rolling Stone magazine article by freelance journalist Tom Curtis. He put forward the theory that AIDS was inadvertantly caused in the late 1950's in the Belgian Congo by Hilary Koprowski's research into a polio vaccine. Although subsequently retracted due to libe issues surrounding its claims, the Rolling Stone article encouraged another freelance journalist, Edward Hooper, to travel to Africa for 7 years of research into this subject. Hooper's research resulted in his publishing a 1999 book, The River, in which he alleged that an experimental oral polio vaccine 
prepared using chimpanzee kidney tissue was the route through which SIV mutated into HIV and started the human AIDS epidemic, some time between 1957 to 1959."

So this example represents a very elaborate form of accommodation where first a new idea was brought in, then it was weakened and finally it was integrated into the text and the theory received its position besides the other theories.

In Wikipedia such processes of accommodation and assimilation often occur. The application of a history flow diagram could be a method which makes such activities visible (Viégas et al. 2004). Such visualizations of Wikipedia articles show that sometimes only new information is merely added to an existing article, and sometimes an article is completely restructured.

\section{Motivational processes in knowledge building}

What motivates people to engage in this collective process of knowledge building? We know from many scenarios where shared databases, forums, or blogs are used for knowledge exchange that people often are reluctant to contribute their own knowledge (Ardichvili et al. 2003; Huber 2001; Jian and Jeffres 2006) because of the costs of the contribution: people have to write down information, they fear embarrassing themselves through publishing information which might contain mistakes, or they may be afraid of losing power if they share information which only they have (Cress et al. 2006). All these problems are described in knowledge-exchange settings, where the main aim is to pool information and to make it accessible (Cress and Hesse 2006; Cress and Kimmerle 2007a; Kimmerle and Cress 2008). In knowledge-building scenarios like Wikipedia this seems to be different. The success and quality of this encyclopedia shows that many people take part in this collaborative process of knowledge building voluntarily and with plenty of effort and enthusiasm. What motivates people to do this?

Following Piaget's model of equilibration we propose that people engage in knowledge building by contributing new information to wikis and by restructuring existing articles because of cognitive conflicts ${ }^{5}$. Using Luhmann's theory, this conflict can be described as irritation. We propose that when people work with a wiki they have to see if their own individual knowledge matches with the information the wiki provides. This matching process can lead to different results: If people feel that the wiki's information is congruent to their individual knowledge then there is no need for equilibration and people do not accommodate or assimilate, either internally nor externally. In contrast, if people feel that the wiki's information differs from their own knowledge, there is a need for equilibration, which people can satisfy by processes of internal or external assimilation or accommodation.

If people realize that important aspects which are part of their knowledge are missing in the wiki they will perhaps externalize these and add them to the wiki (external assimilation). For example, the user who added the CSILE/Knowledge Forum link probably found that the absence of this link was a shortcoming which had to be compensated. If people find that the wiki's information describes aspects which are not part of their individual knowledge they will develop new knowledge by internal assimilation. Probably, users who already knew where to find additional information about CSCL can

\footnotetext{
${ }^{5}$ In this case this is a matter of a social-cognitive conflict since the incongruent information is provided by other people. Socially mediated cognitive conflicts play an important role in approaches of collaborative learning (e.g. Johnson \& Johnson 1987). However, in order to present our ideas on a generic level we stick to the term cognitive conflict.
} 
simply add CSILE/Knowledge Forum to their knowledge about potential sources of information on CSCL.

If people find that their knowledge and the wiki's information are basically incongruent they will accommodate their knowledge (internal accommodation) or revise the wiki article (external accommodation). With internal accommodation, for example, users who did not consider CSCL to be an interdisciplinary field might modify their beliefs on CSCL fundamentally when they read the Wikipedia version from the 23rd of August 2007. Here they read what they did not know beforehand, that "CSCL cuts across research in psychology, computer science, and education". And there are also internalization processes that allow for inferences. If a person who reads the corresponding Wikipedia article comes to know that CSCL is an interdisciplinary field involving psychology amongst other disciplines, and if this person previously knew that CSCL is interested in supporting collaboration, then this person can draw conclusions with respect to how psychological findings can be used for CSCL (e.g. how group majority influences can interfere with collaborative learning and how these perturbing influences might be avoided). With external accommodation a user can decide to revise the article as we have described it in the previous section. The question is whether perceived incongruities lead to equilibration processes in every case. A user who does not care about CSCL research at all would probably not bother to deal with the subject.

Consequently, we propose that the motivation for the described activities of equilibration is a function of two features: The size of the incongruity between the individual's knowledge and the wiki's information on the one hand, and the valence which the topic has for people on the other hand. With regard to the valence we propose a linear relation: the higher people rate the valence of the topic, the higher the perceived cognitive conflict is and the more interest (Krapp 1999) people feel. If a certain topic, such as CSCL research, has a positive valence for people, then the probability raises that they will look into the subject and contribute to its development (for a detailed discussion on the concept of valence cf. Colombetti 2005).

Following Hunt (1965) we propose an inverted u-shaped relation between the incongruity and the cognitive conflict with respect to the incongruity between individual knowledge and the wiki's information. This perspective is displayed in Fig. 3. If the incongruity between the individual's knowledge and the wiki's information is very small, there is no need for equilibration. For example, if a user's knowledge about CSCL

Fig. 3 The inverted u-shaped relation between cognitive conflict and incongruities between an individual's knowledge and the wiki's information. The figure provides this relation for four different levels of valence $(v)$, ranging from a low level to a high level

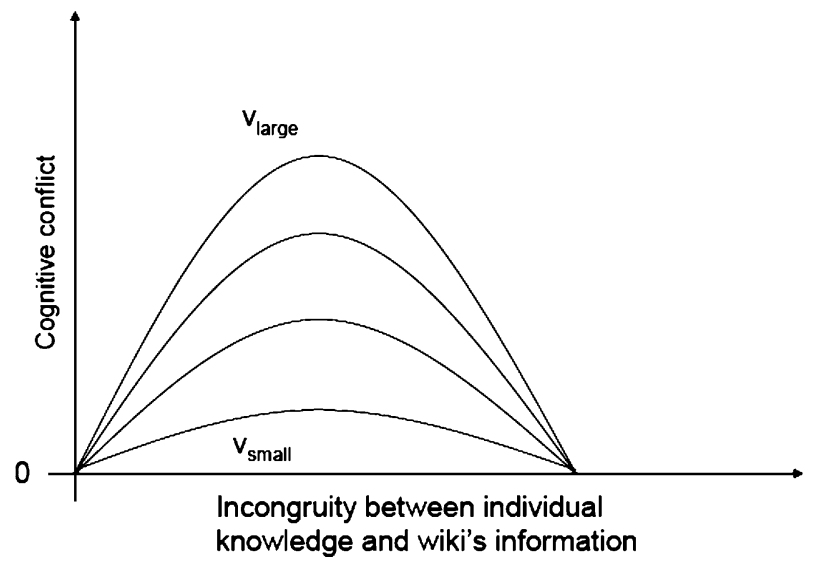


corresponds to the information in the Wikipedia article the user will neither learn anything nor will she or he revise the article. If the incongruity is very large, the information in the wiki and the individual's knowledge will hardly be perceived as describing one and the same topic. This situation will reduce the need for making both congruent. We propose that only a medium-level incongruity causes a cognitive conflict which motivates people to engage in one of the equilibration processes described above.

In this model the incongruity between people's individual knowledge and the wiki's information is the motor of the system's development. In a process of mutual development people learn and enhance their individual knowledge and the wiki improves, becoming more exhaustive and more and more complete. Thus, what can be observed here is a coevolutionary development of social and cognitive systems. This co-evolution of systems is the foundation of collaborative knowledge-building processes. Through equilibration the wiki tends to incorporate more and more knowledge from the users. Through external assimilation the wiki consists of increasingly more information. Through external accommodation processes it enables new understandings, allows for new emergent knowledge, and, accordingly, facilitates collaborative knowledge building.

\section{Conclusions}

In this article we developed a model which helps us to better understand collaborative knowledge building with wikis. For this purpose we combined Luhmann's systems theory with Piaget's cognitive theory. Luhmann's approach is very thorough with respect to social systems, whereas Piaget's theory primarily focuses on cognitive development. Consequently, it was clearly necessary to examine whether the processes described by Piaget could be translated into social systems in order to better understand collaborative knowledge building.

The model attempts to demonstrate the interplay of the social system wiki and individuals' cognitive systems. This consideration of the structural coupling of social and cognitive systems illustrates collaborative knowledge building with artifacts and might be a fertile approach for CSCL research.

Our next steps will comprise experimental tests of the model in various contexts in order to further elaborate on this approach and to expand its empirical foundation. Examinations in controlled settings will allow not only for describing external processes of equilibration but also for analyzing indicators for internal processes of assimilation and accommodation. We believe that this will help us to better understand the interplay of individual learning and computer-supported collaborative knowledge building.

Acknowledgment The authors would like to thank Gerry Stahl and three anonymous reviewers for their comments on an earlier version of this article. An earlier version of this paper appeared in the proceedings of the 7th Computer Supported Collaborative Learning Conference (Cress and Kimmerle 2007b).

\section{References}

Ardichvili, A., Page, V., \& Wentling, T. (2003). Motivation and barriers to participation in virtual knowledgesharing communities of practice. Journal of Knowledge Management, 7, 64-77.

Baddeley, A. D. (1986). Working memory. New York: Oxford University Press.

Baddeley, A. D. (1992). Working memory. Science, 255, 556-559.

Beldarrain, Y. (2006). Distance education trends: Integrating new technologies to foster student interaction and collaboration. Distance Education, 27, 139-153. 
Blood, R. (2002). The weblog handbook: Practical advice on creating and maintaining your blog. Cambridge: Perseus.

Bridsall, W. F. (2007). Web 2.0 as a social movement. Webology, 4(2).

Bruckman, A. (2006). Learning in online communities. In R. K. Sawyer (Ed.), The Cambridge handbook of the learning sciences (pp. 461-472). New York: Cambridge University Press.

Bruns, A., \& Humphreys, S. (2005). Wikis in teaching and assessment: The M/Cyclopedia project. WikiSym 2005-Conference Proceedings of the 2005 International Symposium on Wikis, pp. 25-32.

Bryant, T. (2006). Social software in academia. Educause Quarterly, 29, 61-64.

Ceballos, M.-R., \& Gorricho, J.-L. (2006). P2P file sharing analysis for a better performance. Proceedings of the International Conference on Software Engineering, 2006, 941-944.

Chau, M., \& Xu, J. (2007). Mining communities and their relationships in blogs: A study of online hate groups. International Journal of Human Computer Studies, 65, 57-70.

Chinn, C. A., \& Brewer, W. F. (1993). The role of anomalous data in knowledge acquisition: A theoretical framework and implications for science instruction. Review of Educational Research, 63, 1-49.

Chinn, C. A., \& Brewer, W. F. (1998). An empirical test of a taxonomy of responses to anomalous data in science. Journal of Research in Science Teaching, 35, 623-654.

Chong, N. S. T., \& Yamamoto, M. (2006). Collaborative learning using Wiki and flexnetdiscuss: A pilot study. Proceedings of the Fifth IASTED International Conference on Web-based Education 2006, pp. $150-154$.

Colombetti, G. (2005). Appraising valence. Journal of Consciousness Studies, 12, 103-126.

Craik, F., \& Lockhart, R. (1972). Levels of processing: A framework for memory research. Journal of Verbal Learning \& Verbal Behavior, 11, 671-684.

Cress, U., \& Hesse, F. W. (2006). The social complexity in establishing and sharing information resources. In J. Elen \& R. E. Clark (Eds.), Handling Complexity in Learning Environments: Research and Theory (pp. 67-87). Amsterdam: Elsevier.

Cress, U., \& Kimmerle, J. (2007a). Guidelines and feedback in information exchange: Behavioral anchors and descriptive norms in a social dilemma. Group Dynamics: Theory, Research, and Practice, 11, 42-53.

Cress, U., \& Kimmerle, J. (2007b). A theoretical framework for collaborative knowledge building with wikis: A systemic and cognitive perspective. In Proceedings of the 7th Computer Supported Collaborative Learning Conference (pp. 153-161). New Brunswick: International Society of the Learning Sciences, Inc.

Cress, U., Kimmerle, J., \& Hesse, F. W. (2006). Information exchange with shared databases as a social dilemma: The effect of metaknowledge, bonus systems, and costs. Communication Research, 33, 370-390.

Désilets, A., Paquet, S., \& Vinson, N. G. (2005). Are wikis usable? WikiSym 2005-Conference Proceedings of the 2005 International Symposium on Wikis, pp. 3-15.

Flower, L., \& Hayes, J. R. (1980). The cognition of discovery: Defining a rhetorical problem. College Composition and Communication, 31, 21-32.

Fuchs-Kittowski, F., \& Köhler, A. (2005). Wiki communities in the context of work processes. WikiSym 2005-Conference Proceedings of the 2005 International Symposium on Wikis 2005, pp. 33-39.

Greeno, J. G. (2006). Learning in activity. In R. K. Sawyer (Ed.), The Cambridge handbook of the learning sciences (pp. 79-96). New York: Cambridge University Press.

Guzdial, M., Rick, J., \& Kehoe, C. (2001). Beyond adoption to invention: Teacher-created collaborative activities in higher education. Journal of the Learning Sciences, 10, 265-279.

Hewitt, J., \& Scardamalia, M. (1998). Design principles for distributed knowledge building processes. Educational Psychology Review, 10, 75-96.

Holland, J. H. (1998). Emergence from chaos to order. Redwood City: Addison-Wesley.

Huber, G. P. (2001). Transfer of knowledge in knowledge management systems: Unexplored issues and suggested studies. European Journal of Information Systems, 10, 72-79.

Hunt, J. McV. (1965). Intrinsic motivation and its role in psychological development. In D. Levine (Ed.), Nebraska Symposium of Motivation (pp. 189-282). Lincoln, NE: University of Nebraska Press.

Jian, G., \& Jeffres, L. W. (2006). Understanding employees' willingness to contribute to shared electronic databases: A three-dimensional framework. Communication Research, 33(4), 242-261.

Johnson, S. B. (2001). Emergence. The Connected Lives of Ants, Brains, Cities and Software. Allen Lane: The Penguin.

Johnson, D. W., \& Johnson, R. T. (1987). Creative conflict. Edina, MN: Interaction Book Company.

Joyce, J. (2005). Wiki wiki. Scientific Computing and Instrumentation, 22.

Kafai, Y. B. (2006). Constructionism. In R. K. Sawyer (Ed.), The Cambridge handbook of the learning sciences (pp. 35-46). New York: Cambridge University Press.

Kali, Y. (2006). Collaborative knowledge building using the Design Principles Database. International Journal of Computer-Supported Collaborative Learning, 1, 187-201. 
Kesim, E., \& Agaoglu, E. (2007). A paradigm shift in distance education: Web 2.0 and social software. Turkish Online Journal of Distance Education, 8, 66-75.

Kim, S.-H., Han, H.-S., \& Han, S. (2006). The study on effective programming learning using wiki community systems. WSEAS Transactions on Information Science and Applications, 3(8), 1495-1500.

Kimmerle, J., \& Cress, U. (2008). Group awareness and self-presentation in computer-supported information exchange. International Journal of Computer-Supported Collaborative Learning (in press). DOI 10.1007/s11412-007-9027-z.

Klein, P. D. (1999). Reopening inquiry into cognitive processes in writing-to-learn. Educational Psychology Review, 11, 203-270.

Köhler, A., \& Fuchs-Kittowski, F. (2005). Integration of communities into process-oriented structures. Journal of Universal Computer Science, 11, 410-425.

Kolbitsch, J., \& Maurer, H. (2006). The transformation of the web: How emerging communities shape the information we consume. Journal of Universal Computer Science, 12(2), 187-213.

Korfiatis, N. T., Poulos, M., \& Bokos, G. (2006). Evaluating authoritative sources using social networks: An insight from Wikipedia. Online Information Review, 30, 252-262.

Krapp, A. (1999). Interest, motivation and learning: An educational-psychological perspective. European Journal of Psychology of Education, 14(1), 23-40.

Lee, E. Y. C., Chan, C. K. K., \& Van Aalst, J. (2006). Students assessing their own collaborative knowledge building. International Journal of Computer-Supported Collaborative Learning, 1, 57-87.

Leuf, B., \& Cunningham, W. (2001). The wiki way. Quick collaboration on the web. Boston: Addison-Wesley.

Lih, A. (2004). Wikipedia as participatory journalism: Reliable sources? Metrics for evaluating collaborative media as a news resource. Proceedings of the International Symposium on Online Journalism.

Lin, S.-C., Chen, Y.-C., \& Yu, C.-Y. (2006). Application of wiki collaboration system for value adding and knowledge aggregation in a digital archive project. Journal of Educational Media and Library Science, $43,285-307$.

Luhmann, N. (1984). Soziale Systeme. Grundriss einer allgemeinen Theorie. Frankfurt am Main: Suhrkamp.

Luhmann, N. (1986). The autopoiesis of social systems. In F. Geyer \& J. Van der Zouwen (Eds.), Sociocybernetic paradoxes (pp. 172-192). London: Sage.

Luhmann, N. (1990). Essays on self-reference. New York and Oxford: Columbia University Press.

Luhmann, N. (1995). Social systems. Stanford: Stanford University Press.

Luhmann, N. (1997). Die Gesellschaft der Gesellschaft. Frankfurt am Main: Suhrkamp.

Majchrzak, A., Wagner, C., \& Yates, D. (2006) Corporate wiki users: Results of a survey. Proceedings of WikiSym '06-2006 International Symposium on Wikis 2006, pp. 99-104.

Makice, K. (2006). PoliticWiki: Exploring communal politics. Proceedings of WikiSym'06-2006 International Symposium on Wikis 2006, pp. 105-118.

Maturana, H., \& Varela, F. (1980). Autopoiesis and cognition. Dodrecht: Reidel.

Maurer, H., \& Tochtermann, K. (2002). On a new powerful model for knowledge management and its applications. Journal of Universal Computer Science, 8(1), 85-96.

Moore, T. D., \& Serva, M. A. (2007). Understanding member motivation for contributing to different types of virtual communities: A proposed framework. Proceedings of the 2007 ACM SIGMIS Computer Personnel Research Conference: The Global Information Technology Workforce, SIGMIS-CPR 2007, 153-158.

Murugesan, S. (2007). Understanding Web 2.0. IT Professional, 9, 34-41.

Norman, D. A. (1991). Cognitive artifacts. In J. M. Carroll (Ed.), Designing Interaction: Psychology at the Human-Computer Interface (pp. 17-38). Cambridge: University Press.

Notari, M. (2006). How to use a Wiki in education: Wiki based effective constructive learning. Proceedings of WikiSym '06-2006 International Symposium on Wikis 2006, pp. 131-132.

Oshima, J., Oshima, R., Murayama, I., Inagaki, S., Takenaka, M., Yamamoto, T., et al. (2006). Knowledgebuilding activity structures in Japanese elementary science pedagogy. International Journal of Computer-Supported Collaborative Learning, 1, 229-246.

Papert, S. (1980). Mindstorms. New York: Basic Books.

Papert, S. (1987). Computer criticism versus technocentric thinking. Educational Researcher, 16(1), 24-28.

Papert, S. (1993). The children's machine: Rethinking school in the age of the computer. New York: Basic Books.

Papert, S. (1997). Tinkering towards utopia: A century of public school reform. Journal of the Learning Sciences, 6(4), 417-427.

Pentzold, C., \& Seidenglanz, S. (2006). Foucault@Wiki: First steps towards a conceptual framework for the analysis of wiki discourses. Proceedings of WikiSym '06-2006 International Symposium on Wikis 2006, pp. 59-68.

Piaget, J. (1970). Piaget's theory. In P. H. Mussen (Ed.), Carmichael's manual of child psychology (pp. 703732). New York: Wiley. 
Piaget, J. (1977a). The development of thought: Equilibration of cognitive structures. New York: The Viking Press.

Piaget, J. (1977b). Problems of equilibration. In M. H. Appel \& L. S. Goldberg (Eds.), Topics in cognitive development, Vol. 1 (pp. 3-14). New York: Plenum.

Raitman, R., Augar, N., \& Zhou, W. (2005). Employing wikis for online collaboration in the e-learning environment: Case study. Proceedings-3rd International Conference on Information Technology and Applications, ICITA 2005 II, art. no. 1488944, pp. 142-146.

Ras, E., Avram, G., Waterson, P., \& Weibelzahl, S. (2005). Using weblogs for knowledge sharing and learning in information spaces. Journal of Universal Computer Science, 11, 394-409.

Reinhold, S. (2006). Wikitrails: Augmenting Wiki structure for collaborative, interdisciplinary learning. Proceedings of WikiSym '06-2006 International Symposium on Wikis 2006, pp. 47-57.

Richardson, W. (2006). Blogs, wikis, procasts, and other powerful web tools for classrooms. Thousand Oaks: Corwin.

Rick, J., \& Guzdial, M. (2006). Situating CoWeb: A scholarship of application. International Journal of Computer-Supported Collaborative Learning, 1, 89-115.

Rodriguez, P., Tan, S.-M., \& Gkantsidis, C. (2005). On the feasibility of commercial, legal P2P content distribution. Proceedings of the IEEE 10th International Workshop on Web Content Caching and Distribution. Sophia Antipolis, France.

Scardamalia, M. (2002). Collective cognitive responsibility for the advancement of knowledge. In B. Smith (Ed.), Liberal education in a knowledge society (pp. 67-98). Chicago: Open Court.

Scardamalia, M., \& Bereiter, C. (1994). Computer support for knowledge-building communities. The Journal of the Learning Sciences, 3(3), 265-283.

Scardamalia, M., \& Bereiter, C. (1996). Student communities for the advancement of knowledge. Communications of the ACM, 39, 36-37.

Scardamalia, M., \& Bereiter, C. (2003). Knowledge Building. In J. W. Guthrie (Ed.), Encyclopedia of Education (pp. 1370-1373). New York: Macmillan.

Stahl, G. (2002). Contributions to a theoretical framework for CSCL. In G. Stahl (Ed.), Proceedings of CSCL 2002 (pp. 62-71). USA: Boulder.

Sweetser, K. D., \& Metzgar, E. (2007). Communicating during crisis: Use of blogs as a relationship management tool. Public Relations Review, 33, 340-342.

Tredinnick, L. (2006). Web 2.0 and business: A pointer to the intranets of the future? Business Information Review, 23, 228-234.

Varela, F. J., Maturana, H. R., \& Uribe, R. (1974). Autopoiesis: The organization of living systems, its characterization and a model. Biosystems, 5, 187-196.

Viégas, F. B., Wattenberg, M., \& Dave, K. (2004). Studying cooperation and conflict between authors with history flow visualizations. In Proceedings of the SIGCHI Conference on Human Factors in Computing Systems (pp. 575-582). Vienna, Austria.

von Bertalanffy, L. (1950). An Outline of general system theory. British Journal for the Philosophy of Science, 1, 139-164.

von Bertalanffy, L. (1968). General system theory: Foundations, development, applications. New York: George Braziller.

Wagner, C. (2006). Breaking the knowledge acquisition bottleneck through conversational knowledge management. Information Resources Management Journal, 19, 70-83.

Wagner, C., \& Bolloju, N. (2005). Supporting knowledge management in organizations with conversational technologies: Discussion forums, weblogs, and wikis. Journal of Database Management, 16, i-viii.

Wagner, C., \& Majchrzak, A. (2007). Enabling customer-centricity using wikis and the wiki way. Journal of Management Information Systems, 23, 17-43.

Wang, C.-M., \& Turner, D. (2005). Extending the wiki paradigm for use in the classroom. International Conference on Information Technology: Coding Computing, ITCC, 1, 255-259.

Ward, R. (2006). Blogs and wikis: A personal journey. Business Information Review, 23, 235-240.

Wasko, M. M., \& Faraj, S. (2005). Why should I share? Examining knowledge contribution in networks of practice. MIS Quarterly, 29, 35-58.

Webb, N. M. (1982). Student interaction and learning in small groups. Review of Educational Research, 52 (3), 421-445.

Wilson, B., \& Lowry, M. (2001). Constructivist learning on the web. In E. J. Burge (Ed.), The strategic use of learning technologies (pp. 79-88). San Francisco, CA: Jossey-Bass.

Yukawa, J. (2006). Co-reflection in online learning: Collaborative critical thinking as narrative. International Journal of Computer-Supported Collaborative Learning, 1, 203-228. 